\title{
THE FIRE OF NOTRE DAME: ECONOMIC LESSONS LEARNED
}

\author{
WADAD KATHY TANNOUS \\ School of Business, Western Sydney University, Australia
}

\begin{abstract}
On the 14th April 2019, a major fire damaged Notre-Dame Cathedral in France. The damage was estimated to the value of billions of dollars in terms of lost art and built material. This study aims to assess the impact of this event and its predictability and potential preventability. The study uses primary data from surveys of response agencies, response personnel, structural engineers, fire engineers, insurance assessors, and heritage specialists. The study examines the economic cost of the fire in the immediacy of the incident, the short term and the long term. In addition, the environmental impact of the fire incident is examined. This includes the internal environment of the church, the chemicals that may be used in the restoration, the chemicals that may be released into the general environment and what they mean for response agency personnel and the impact on their health. The economic impact of the fire of Notre Dame is significant and will be long lasting on the residents in the immediate surroundings and wider vicinity of the church; the response workers; and on the country. Our findings provide lessons for assessing the costs to implementing preventive measures and improving fire preparation for older style buildings. In particular, measuring the economic costs of iconic buildings, such as Notre-Dame Cathedral, whose damage or destruction are horrific for the short and long term.

Keywords: disaster, fire safety, environmental impact, economic costs.
\end{abstract}

\section{INTRODUCTION}

On 15th April 2019 at 6:18 pm a fire began in the roof of the French gothic Notre-Dame Cathedral in Paris France [1] with the first alert was sound at $6: 20 \mathrm{pm}$ local time [2]. The landmark's famous spire and vaulted interior roof (known as "the forest") provided ample fuel for the flames as they were built with wood, primarily 13th century oak trees [3]. Over five hundred firefighters responded and it took nine hours to control the fire and fifteen hours until the fire was extinguished [3], [4].

Notre-Dame cathedral is a Parisian icon that had inspired artists, poets, novelists and Francophiles over many generations [5]. It is more than just a place of worship but also an architectural marvel for others [6]. It has further reach as being the mascot of a Disney movie, and a backdrop for many other recent and past movies, and as Victor Hugo novel The Hunchback of Notre Dame, 1931 [7], [8]. The fire incident has been described as a devastation for the building but also for the city. Notre-Dame Cathedral is the single most visited cultural site in Paris with 12 million visitors in 2017 double the number that visit the Eiffel Tower, with 6.2 million visitors in the same year [9]. The building is over 850 years old and its famous spire of the cathedral was undergoing $€ 6$ million restoration project [10]. Notre Dame had an extensive fire warning system that took six years to put together and involved thousands of pages of diagrams, maps, spreadsheets and contracts [11]. The system was based on prevention and detection with two guards on site monitoring the roof structure, day and night and having it checked regularly [12]. The fire alarms in Notre-Dame did not notify the fire department but alerted the guard of the fire. A number of subsequent events resulted in significant delay in the alerting the response agencies including the guard checking on the wrong church and the need for the personal check of the attic to confirm that the fire was there that involved the climb of steep set of stairs [11], [12]. The fire in Notre 
Dame has been described as a symptom neglect of the building [13]. Paris public prosecutor's office said that their preliminary findings suggested the fire had been started accidentally.

The fire safety experts underestimated the risk from fire but also the costs if and when the incident did occur [12]. In addition, they were most conservative in their approach to preserving the historic wooden structure in unadulterated form that they did not install protective measures of sprinklers or fire walls. Even back to base alarms were not installed due to concerns of false alarms.

The costs of the fire are still being determined and for some of the destroyed contents, they are priceless. However, the economic costs of this incident extend beyond the building and extend to the impact of this event on tourism to Paris and France itself. In addition, unplanned costs and effects have also started to surface from this incident of lead contamination. Notre-Dame's spire and roof housed upwards of 400 tonnes of lead which melted in the fire, releasing toxic dust and particles across Île de la Cité and the surrounding neighbourhoods [14], [15].

Section 2 will discuss the damage that Notre-Dame cathedral sustained from the fire incident and touch on the resources used to contain the incident. Section 3 will describe the environmental costs and potential ongoing health costs from the lead contamination. Section 4 will detail the restoration process and challenges. Section 5 will provide a simulation model of the potential lost income, most conservatively, over the planned five-year restoration period. The final section will describe the lessons learned from this event.

\section{DAMAGE TO NOTRE-DAME CATHEDRAL}

\subsection{Damage done}

While the Notre-Dame cathedral received extensive damage in the fire, it is difficult to make a true estimate of the exact cost of the damage. As Walt [16] explained, "two-thirds of the roof collapsed in the fire, in the process also destroying some of the centuries-old statues of saints that were perched on the spire... part of the nave and the choir are also gone" [16]. The ceiling vaults were made of 5,000-year-old oak trees had seen some of the most severe damage, adding that much of the damage to the cathedral and its content was "difficult to calculate" as they are considered "priceless" [16]. One clear loss was the famous spire of the cathedral. When the fire broke out, Notre-Dame's spire was undergoing a $€ 6$ million restoration project [10]. As a result of this, many valuable items, including sixteen copper statues of saints, had fortunately been removed from the premises mere days before the fire erupted [17]. French Culture Minister Franck Riester stated that many of France's "most precious treasures" were spared from destruction, including the crown of thorns, allegedly worn by Jesus, and the tunic of St. Louis [17], [18]. The famous stained glass Rose Windows were spared from catastrophe, as well as the organ. The large artwork titled the "May de Notre-Dame", along with other artworks, were moved to the Louvre museum, where they would "be dehumidified, protected, conserved and restored" [19]. While major parts of the church, as well as relics and artworks inside, were destroyed or damaged by fire, smoke and water, it is still considered to be too early to estimate the cost of the damage [20]. The cathedral's two bell towers and outer walls stood firm, while their insides and the upper structure were eviscerated by the blaze [2].

\section{ENVIRONMENTAL COSTS}

Notre-Dame's spire and roof housed upwards of 400 tonnes of lead that coated Notre-Dame Cathedral's spire and roof framing was released into the air and surrounding environment 
across Île de la Cité and the surrounding neighbourhoods when the cathedral burned [14], [15], [21]. The vaulted ceiling is just below the roof and had been detailed to have stopped the lead from falling out of the roof space. It was trapped close to the blaze that burned at over $800^{\circ} \mathrm{C}$ that some of the lead would have vaporized and oxidized to feed more heat into the reaction and accelerating the vaporization and oxidization [21], [22]. The city officials issues no warning to residents of any potential dangers related to lead contamination; in fact, it was not until April 27, nearly two weeks after the fire, that the first warning of elevated lead levels in the area surrounding Notre-Dame was issued [14].

On 27th April, the Parisian police issued a warning of high levels of neurotoxic lead dust in the immediate area around the church. The areas around the cathedral, such as the gardens, have been closed with advice that residents in the area use wet wipes to remove dust from surface and furniture. Some of the fine particles including lead oxides may have deposited on surrounding soils or were transported by wind. Another part of the lead is assumed to have dispersed in the Seine river given the location of the cathedral on a river island called "Île de la Cité" and the large amount of water that was used by the firefighters on the blaze [22]. The concern raised is the impact of lead vaporization and lead poisoning. The first results provided by the French authorities of lead $(\mathrm{Pb})$ soil concentration on the order of $10 \mathrm{~g} \mathrm{~kg}^{-1}$ that demonstrates the intensity of lead contamination and likely other related metals such as antimony or arsenic [22]. The areas showing high levels of lead contamination were the plaza and gardens surrounding Notre-Dame as well as inside the cathedral itself, all of which were already closed to the public [23].

A number of prevention and protection of the population have been undertaken to minimize the health consequences from lead pollution. In the 18th July 2019 Health Notice by the Agence Régionale de Santé, samples were be taken from all establishments that have young children near the cathedral or a road network where a high value of lead $\left(>5000 \mu \mathrm{g} / \mathrm{m}^{2}\right)$ was found in the dust [24] and rates of $>1000 \mu \mathrm{g} / \mathrm{m}^{2}$ for outdoor spaces of schools and other types of facilities [25]. Samples were taken of indoor spaces and playgrounds and when values were abnormal, work measures and cleaning were undertaken with subsequent analyses to ensure that the measures had been effective [24]. Three elementary schools and one kindergarten were found to have rates above $1000 \mu \mathrm{g} / \mathrm{m}^{2}$ requiring excavation of the playground, access to be removed and coverage of the patio by flexible slabs to be made. In addition, the City of Paris widen the geographical scope of testing and measurements [25]. The costs remediating the playground at one school Saint-Benoit was 200,000 $€$ with additional costs of treating the polluted bitumen as these hazardous material [25].

The risk from lead poisoning is predominately with young children, especially those under the age of 7, and pregnant women and the children they carry [25]. Health authorities aim to protect cathedral restoration workers and to continuously conduct longer-term testing of the exposed areas [21]. The forecourt of Notre-Dame and the adjacent streets have been identified to require specific treatment as they measured very high concentration of lead [25]. In late July, clean-up work at the site was stopped with workers sent home from the site due to concerns that the anti-contamination measures may be insufficient [26].

In June, a child living on Île de la Cité was found to have high levels of lead in his blood. This prompted authorities to suggest blood tests for pregnant women and families with kids under seven years old living on Île de la Cité [27]. Officials, however, maintained that lead contamination was not a problem in the areas around Notre-Dame; on July 5, Paris's regional health office stated that "all the interior samplings taken in the residences of families living near the cathedral are beneath regulation levels" [14]. It was not until weeks later that the same agency declared, "lead pollution is very significant on Île de la Cite and around the Cathedral", but maintained that "no health impact that can be attributed to the pollution 
caused by the fire has been thus far observed" [14]. At the same time, an environmental group called Robin de Bois filed a lawsuit against French authorities, accusing them of minimising the danger and failing to provide adequate warnings to local residents. The head of the organisation stated that lead contamination could easily spread within a mile of the cathedral, affecting Paris's 6th arrondissement, including nearby schools and the Place Saint-Michel, as well as the Left Bank, an area on the southside of the Seine. Robin de Bois observed cafes and bouquinistes on the Left Bank still operating as usual and pedestrians walking right up to the barricaded plaza around Notre-Dame to take photos [14], [28]. In early August, decontamination efforts began for schools and nurseries within several hundred metres of the cathedral, and Notre-Dame itself was sealed off on August 13 to commence clean-up operations [15], [29]. This was the second attempt at decontaminating the cathedral after efforts in July were halted due to concerns around lead poisoning. Concurrently, 162 local children were tested for lead contamination - 16 were found to have levels that need monitoring and one child was found to have a worryingly high level, but officials said it was unclear if this was linked to Notre Dame or his home [15].

France's healthcare system is largely financed by government health insurance: in 2015, France spent $11.5 \%$ of its GDP on healthcare, the third highest in all of Europe [30]. The risk of lead poisoning as a result of the Notre-Dame fire could bear the government with an increased financial burden, on top of the already astounding costs of rebuilding the cathedral. As lead is a cumulative toxin, risk of poisoning increases with length of exposure, and seemingly "safe" levels with no apparent symptoms can still lead to irreversible neurological and behavioural damage [31]. The attempts to decontaminate Notre-Dame and the surrounding areas remain strong, but we will not know the effects of the potential contamination for years to come.

\section{COSTS AND TIME OF OTHER RESTORATIONS}

Upon news of the fire, pledges poured in immediately for the costs of reconstruction and reached over $€ 750$ million in just the first 10 days [32]. This amount is equivalent to nearly three years of France's entire national restoration budget [33]. Several months on, questions remain as to the cost and viability of reconstruction as well as the likely time frame. The original structure took over 200 years to build and was in need of significant repairs and restorations prior to the devastating impacts of the recent fire [34].

Accurately estimating the likely cost and time frame of repairs to the cathedral is difficult for a number of reasons, one being concerns about the availability of resources to recreate damaged areas. In particular, the original wooden ceiling was made from approximately 5,000 primeval oak trees which simply no longer exist in such large quantities. Another reason is the limited number of tradespeople with the skills and techniques utilised to achieve certain original features of the building to the standard they were [35]. Furthermore, the building is not considered safe or structurally sound enough for workers to enter, inspect and determine the true extent of the damage. Franck Riester, France's Culture Minister, said Notre-Dame remained unstable and vulnerable - in particular its ceiling, which can potentially still collapse [36]. This initial step of inspection, cleanup and stabilising the remaining structure has already experienced delays due to concerns about lead contamination from the melted roof.

Work has only recently recommenced with strict new lead-protection measures in place to protect workers onsite, including "throwaway full-body clothing, obligatory showers and a decontamination zone to ensure that no one tracks pollution outside the site" [37]. These important measures will likely remain throughout the duration of the project but will nonetheless make for a more costly, complicated and lengthy process. 


\subsection{Time frame: Looking to precedents and determining approach}

Despite President Macron's desire to have Notre Dame rebuilt in 5 years, ostensibly in time for the 2024 Paris Olympics, architects and reconstruction experts were quick to cast doubts on the viability of this time frame. Frédéric Létoffé, president of a group of companies specialising in the restoration of historic buildings and monuments, warned that a comprehensive restoration of Notre-Dame would likely take longer, between 10 and 15 years [10]. Eric Fischer, who oversaw the restoration of France's 1,000-year-old Strasbourg Cathedral, indicated it might take decades [38]. Medieval historian Mickaël Wilmart cited precedents of smaller buildings from the same era that had taken longer to restore:

The Nantes Cathedral suffered a similar roof fire in January of 1972. It was closed for three years while the roof was rebuilt. But it took another ten years of further work before it was completely restored... and the parliament in [the French region of] Brittany [which burned in 1994] took five years, and it wasn't as big as Notre-Dame [35].

Marine de la Guerrande, an architect with the Ile de France Order of Architects, warned that it was far too early to determine a timeline. She cited a 17 th-century building, nowhere near the scale of Notre-Dame but similarly devastated by fire that took five years to rebuild, needing "two years just for initial conservation measures, to monitor and dry the structure" [35]. This is due to the risk of thermal shock caused by cold water proceeding the fire's powerful heat, which can cause fractures and corrosion to the stone. If this were the case at Notre-Dame, the entire vault may need to be destroyed and rebuilt, which would obviously add a large amount of work, time and cost to the project [35]. However, some experts are advocating that with enormous support the project could be finished in the ambitious time frame. One of the key determiners will be the approach taken to reconstructing the building, which is yet to be resolved. If there are attempts to recreate and restore Notre-Dame using original materials and techniques, there will be associated challenges and a significant investment of time and expertise required. However, the French government is open to innovation in design, technique and materials - at least for the spire, a 19th-century addition [3]. They are running an open, worldwide competition for architects to submit a design either for rebuilding the old spire or for a new, modern spire [10]. Many experts have indicated that openness to the innovative use of technology in design, materials and construction will be vital to meeting the five-year time frame put forward [34].

\subsection{Costs: Still no official estimate and even educated guesses differ}

No official cost estimate has been put forth by the French government. However, since the fire, several external organisations have made estimates regarding the cost of reconstruction. One estimate came from Untec, the national union representing construction economists, who indicated costs of reconstruction would likely be between $€ 300$ and $€ 600$ million. Robert Read, head of insurance agency Hiscox, stated costs could reach over $€ 1 \mathrm{bn}$, but cautioned making estimates this early on without a comprehensive understanding of the potential consequences [32]. While field experts can make estimates, the reality is that these are not based on an actual assessment of the site for damages. The cost alone of securing the building to make it safe for restoration workers to enter is estimated to reach $€ 20$ million [39]. Even those working on the official restoration team that have been able to enter the cathedral remain unable to accurately assess the costs of restoring Notre-Dame due to many of the same reasons discussed above. Both cost and time frame are inextricably linked and 
ultimately unknowable until Notre-Dame is safe for inspection and assessment and until decisions are made about the approach to reconstruction from the perspective of design, techniques, materials and quality. What is clear is that there are many important decisions to be made regarding the future of Notre-Dame and only then can we understand the true cost and time it will take to see this vision realised.

Decisions to be made are significant and include which of the 19th-century additions, such as the spire that was destroyed in the fire, will it be replicated or replaced [4]. Because of the church's significance, history, and religious worth, renovators will need to consult with scholars, architects and church officials [2].

\section{SIMULATION MODEL OF FUTURE LOST INCOME}

The number of tourists visiting France from the year 2013 to 2018 was collected from DGE and Banque de France, EVE survey of visitors from abroad. The number of tourists visiting the Notre-Dame cathedral was 12 million in 2017 which was about $13.82 \%$ of the total tourists coming to France. We have calculated the number of tourists visiting the Cathedral for the years 2013-2018, assuming that the percentage does not vary significantly across time. We have forecasted the estimated number of visits to this tourist attraction in three steps. First, we calculate the annual percentage changes in the number of tourists for the Cathedral from the available data. Secondly, we estimate the average annual growth rate. In the last step, we forecast the number of tourists visiting the Notre-Dame cathedral by summing up the previous year visitors and change in visitors for a given year. The forecast provides the estimated number of visitors if the fire event did not occur. We can make different assumptions in the reduction of the number of tourists in different years and provide estimates of lost revenue in different sectors.

\subsection{Lost revenue from souvenirs}

For the years 2019-2025, we have estimated revenue lost from souvenir sale assuming the reduction in number of tourists at the Cathedral from $20 \%$ to $70 \%$. In case of 2019 , the calculation is done after the incident. The average spending per tourist on souvenir at this attraction assumed to vary from EUR 10 to EUR 40. We have also included different scenarios where the percentage of people buying these souvenirs varies from $20 \%$ to $70 \%$, while visiting the Notre-Dame cathedral. We divided our estimates into three scenarios: best case, base case and worse case. If the reduction in number of tourists is $20 \%$, we define it as best case, whereas $50 \%$ and $70 \%$ reductions are defined as base case and worse case respectively.

Table 1 shows revenue lost from souvenir sales which would have otherwise taken place in the absence of the fire incident.

\subsection{Lost revenue from entry fees}

We have estimated the fees lost by multiplying the number of tourists with relevant fees of entry to the Tower or the Crypt or the Treasury of the Cathedral. We have assumed the same scenarios for the calculation of revenue forgone. We use the average fees of entry to the Tower and the Crypt are EUR 9 (average for EU and non-EU) and EUR 7 along with the entry fee to the Treasury is EUR 3 in the calculation. We have also included different scenarios where the percentage of people visiting these places within the Cathedral varies from $20 \%$ to $70 \%$. Table 2 shows revenue lost from entry fees which would have otherwise earned in the absence if the event of fire did not happen. 


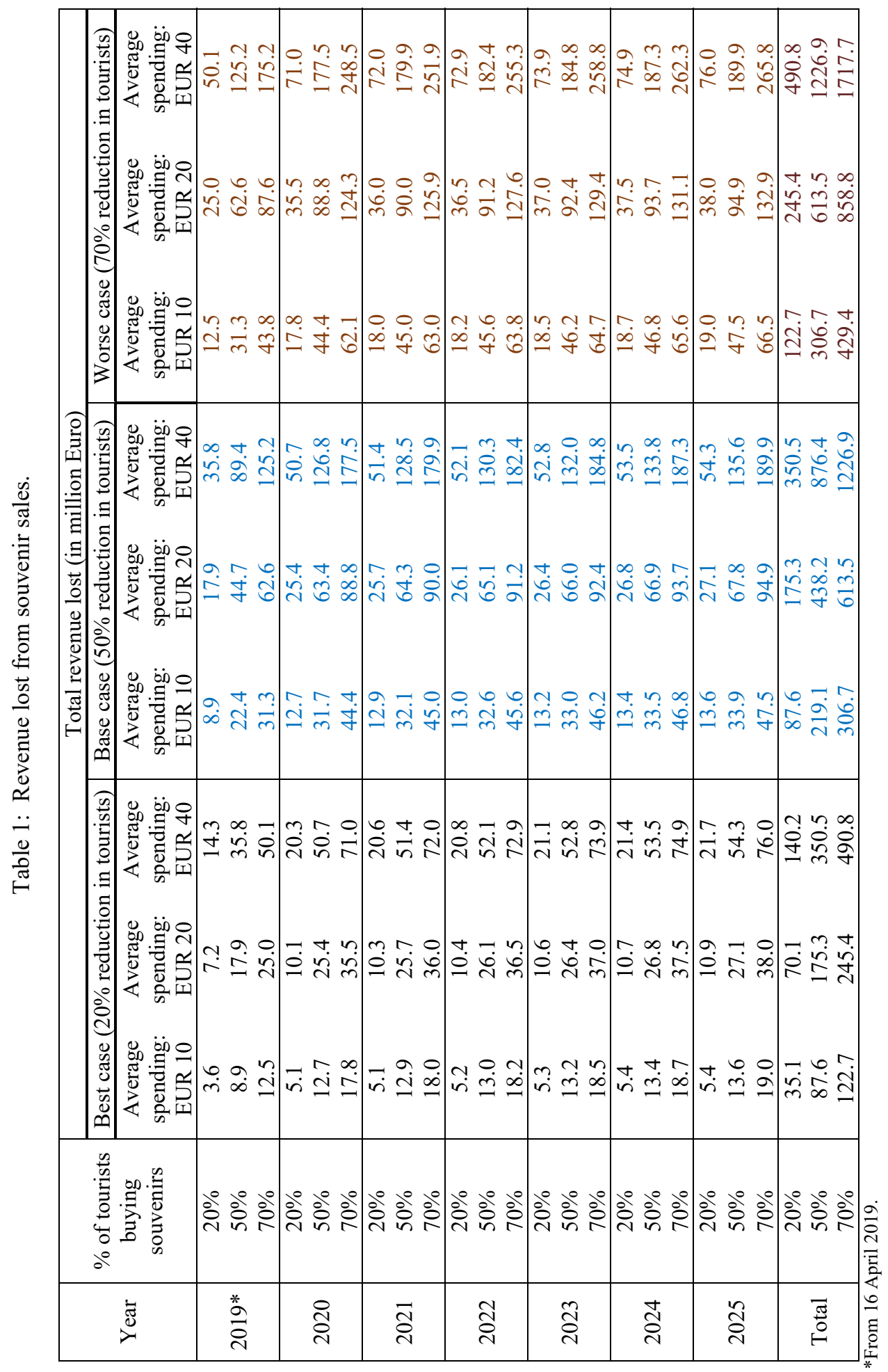




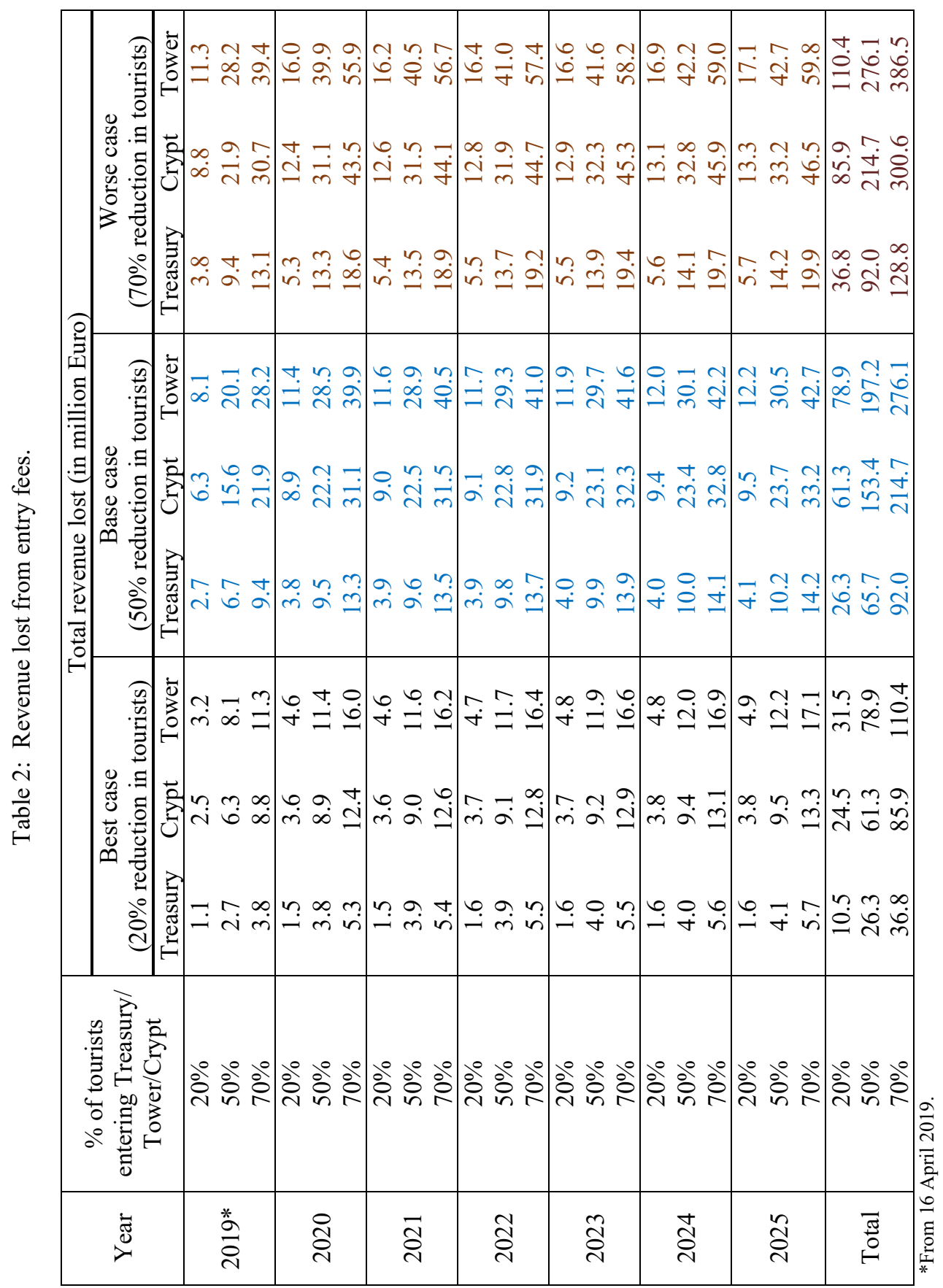




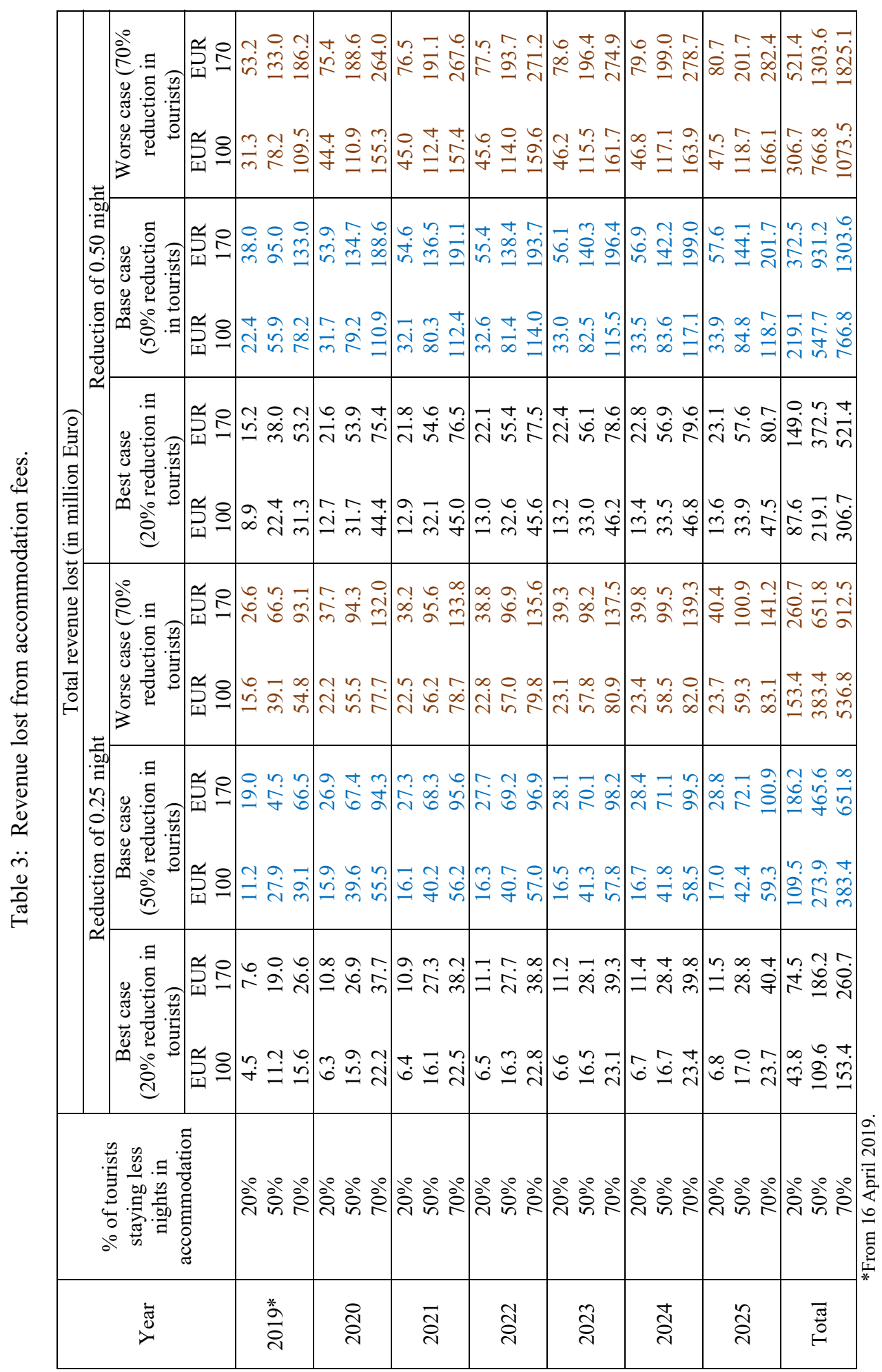




\subsection{Revenue lost from accommodation fees}

We have calculated and forecasted the forgone income due to the fire incident of the Notre-Dame cathedral with three scenarios. In this case we assume two different average prices of accommodation: EUR 100 and EUR 170. Table 3 shows the estimated forgone revenue for the years 2019-2025.

\section{LESSONS LEARNED FROM NOTRE-DAME FIRE}

The reaction of onlookers and the extensive news coverage worldwide is a demonstration of the significance of Notre Dame as a structure. It is also noted as a symbol of Christianity and the people's ability to feel a personal and emotional connection through the building to God [6]. The appropriate maintenance of older structures is often done without appropriate reference to scientific evidence such as the addition of a fire sprinkler system. This is often avoided due to erroneous concerns that doing so might alter the historical authenticity of a building, or water would damage the building and its historical collections, or associated electrical wiring would present a fire hazard [12], [13]. The reasons for not putting in place the fire prevention measures is due to cost or aesthetics. However, the cost of not minimising risk is priceless, as once it is gone, the original is gone forever. Any rebuilding is just a rebuild and not original. In addition, for older buildings like Notre Dame, the costs of fire need to be viewed from multiple dimensions inclusive of the environmental and health impact. The economic costs of the fire have been discussed mildly in this paper as the full damage is yet to be understood and with every day new information is being released. One of the groups that needs to be monitored closely is the first responders and people who work or live in the vicinity with regards to their health and ongoing effects of exposures to different toxicities.

\section{ACKNOWLEDGEMENT}

This research acknowledges support provided by Moin Uddin Ahmed and Kathleen Quilty.

\section{REFERENCES}

[1] Chung, F., How did the Notre Dame Cathedral blaze start? 16 April 2019. www.news.com.au/travel/travel-updates/how-did-the-notre-dame-cathedral-blazestart/news-story/0047a8551 efcbe8574ff958c5c641904. Accessed on: 20 Aug. 2019.

[2] El-Bawab, N., Newburger, E. \& Steinberg, M., Notre Dame will be rebuilt within the next five years, French President Emmanuel Macron says. CNBC World News, 16 April 2019.

www.cnbc.com/2019/04/15/paris-notre-dame-cathedral-on-fire-reuters.html.

Accessed on: 24 Aug. 2019.

[3] Vandoorne, S., Bell, M. \& Fox, K., Devastating Notre Dame blaze was "likely accidental”. CNN, 16 April 2019. https://edition.cnn.com/2019/04/16/europe/notredame-cathedral-fire-intl/index.html. Accessed on: 30 Aug. 2019.

[4] El-Bawab, N., Restoration of the Notre Dame Cathedral could take years and cost upward of \$1 billion, experts say. CNBC, 17 April 2019.

www.cnbc.com/2019/04/17/notre-dame-fire-experts-weigh-in-on-timeline-and-costof-restoration.html. Accessed on: 1 Sep. 2019.

[5] Morshed, A.Z., The wrong kind of fire. The Daily Star, 18 April 2019. www.thedailystar.net/opinion/the-grudging-urbanist/news/the-wrong-kind-fire1730437. Accessed on: 30 Aug. 2019. 
[6] Latham, M.D., Gothic cathedrals: A shift in Christians' relationship with God. Young Historians Conference 2019, Portland State University, Oregon, 2019.

[7] Gross, M., Uncovering the roots of religion. Current Biology, 29(11), pp. R426-R429, 2019.

[8] Sanchez, O., Notre Dame Cathedral: 14 classic movie scenes at the Paris landmark. The Wrap, 15 April 2019. www.thewrap.com/notre-dame-cathedral-10-films-shot-setparis-landmark/. Accessed on: 30 Aug. 2019.

[9] Statista, Number of visitors to cultural sites in Paris in 2017, 2019. www.statista.com/ statistics/991935/cultural-sites-attendance-paris-france/. Accessed on: 2 Sep. 2019.

[10] Prisco, J., France announces competition to rebuild Notre Dame's spire. CNN, 17 April 2019.https://edition.cnn.com/style/article/notre-dame-spire-competition-intl/ index.html. Accessed on: 30 Aug. 2019.

[11] Peltier, E., Glanz, J., Grondahl, M., Cai, W., Nossiter, A. \& Alderman, L., Notre-Dame came far closer to collapsing than people knew. This is how it was saved. New York Times, 18 July 2019. www.nytimes.com/interactive/2019/07/16/world/europe/notredame.html. Accessed on: 30 Aug. 2019.

[12] Bennhold, K. \& Glanz, J., Notre-Dames safety planners underestimated the risk, with devestating results. New York Times, 19 April 2019. www.nytimes.com/2019/04/19/ world/europe/notre-dame-fire-safety.html. Accessed on: 1 Sep. 2019.

[13] Wells, J.C., Science for built heritage. Science, 364(6439), p. 413, 2019.

[14] Nossiter, A., Notre-Dame fire released toxic lead that authorities dismissed, lawsuit says. New York Times, 31 July 2019. www.nytimes.com/2019/07/31/world/europe/ notre-dame-fire-lead-lawsuit.html. Accessed on: 30 Aug. 2019.

[15] Willsher, K., Notre Dame cathedral sealed off for huge lead decontamination operation. The Guardian, 13 August 2019. www.theguardian.com/world/2019/aug/13/ notre-dame-fire-lead-contamination-clean-up-begins-around-cathedral. Accessed on: 25 Aug. 2019.

[16] Walt, V., We tried to save Notre Dame too late, says champion of cathedral restoration. Time, 16 April 2019. https://time.com/5571554/paris-fire-notre-dame-shock-damage/. Accessed on: 22 Aug. 2019.

[17] Li, D.K., What was lost and what survived devastating Notre Dame fire. NBC News, 17 April 2019. www.nbcnews.com/news/europe/what-was-lost-what-surviveddevastating-notre-dame-fire-n995026. Accessed on: 20 Aug. 2019.

[18] Gajanan, M., The Notre Dame fire put priceless art and artifacts at risk. Here's what survived - and what didn't. Time, 16 April 2019. https://time.com/5571542/notredame-fire-art-artifacts-lost/. Accessed on: 30 Aug. 2019.

[19] Ries, B. et al., Firefighters saved many precious artworks from the Notre Dame blaze. CNN, 16 April 2019. https://edition.cnn.com/world/live-news/notre-dame-fire/ h_37d7f4960c561e868ce2c03adc111d0d. Accessed on: 30 Aug. 2019.

[20] Lough, R. \& Pineau, E., French President Macron hopes to rebuild Notre-Dame in five years. Reuters, 16 April 2019. www.reuters.com/article/us-france-notredame-probe/ french-president-macron-hopes-to-rebuild-notre-dame-in-five-yearsidUSKCN1RS0AV. Accessed on: 30 Aug. 2019.

[21] Howes, L., Lead contamination risk near Notre-Dame cathedral. American Chemical Society, Report No.: 0009-2347, 30 April 2019.

[22] Le Roux, G., De Vleeschouwer, F., Weiss, D., Masson, O., Pinelli, E. \& Shotyk, W., Learning from the past: Fires, architecture, and environmental lead emissions. Environmental Science \& Technology, 53(15), pp. 8482-8484, 2019. 
[23] Chrisafis, A., Notre Dame fire: Police say air not toxic despite high lead levels on the ground. The Guardian, 10 May 2019. www.theguardian.com/world/2019/may/09/ paris-police-say-no-danger-of-toxic-inhalation-from-air-near-notre-dame. Accessed on: 30 Aug. 2019.

[24] Agence Regionale de Sante, Fire Notre-Dame: Health opinion of 29/08 and situation update, France, 2019.

[25] Ville de Paris, Lead: Update on the situation after the Notre-Dame fire Paris, 2019. www.paris.fr/pages/incendie-de-notre-dame-l-essentiel-concernant-la-pollution-auplomb-7028.

[26] Chrisafis, A., Notre Dame fire: Activists launch lawsuit over "toxic fallout". The Guardian, 30 July 2019. www.theguardian.com/world/2019/jul/30/notre-dame-fireactivists-launch-lawsuit-over-toxic-fallout-paris. Accessed on: 29 Aug. 2019.

[27] Williams, S., Young, pregnant urged to take blood tests for lead after Notre Dame fire. CTVNEWS, 4 June 2019. www.ctvnews.ca/health/young-pregnant-urged-to-takeblood-tests-for-lead-after-notre-dame-fire- 1.4451376 ? cache $=$ yes $\% 3$ FclipId $\%$ 3D86116\%3Fot\%3DAjaxLayout\%3Fot\%3DAjaxLayout. Accessed on: 1 Sep. 2019.

[28] Cigainero, J., Notre Dame repair crews are back to work, but Paris' lead concerns remain. NPR, 20 August 2019. www.npr.org/2019/08/20/752565861/notre-damerepair-crews-are-back-to-work-but-paris-lead-concerns-remain. Accessed on: 23 Aug. 2019.

[29] Associated Press in Paris, Notre Dame fire: Lead decontamination of schools begins. The Guardian, 8 August 2019. www.theguardian.com/world/2019/aug/08/notredame-fire-lead-decontamination-of-schools-begins. Accessed on: 30 Aug. 2019.

[30] Ballas, D., Dorling, D. \& Hennig, B., The Human Atlas of Europe, Policy Press: Bristol, 2017.

[31] World Health Organization, Exposure to Lead: A Major Public Health Concern, World Health Organization: Switzerland, 2010.

[32] Cuddy, A. \& Boelpaep, B., Notre-Dame fire: Has too much money been given to rebuild it? BBC News, 25 April 2019. www.bbc.com/news/world-europe-48039770. Accessed on: 2 Sep. 2019.

[33] Casert, R., The Notre-Dame fire was a warning bell, but will Europe listen? The Globe and Mail, 22 April 2019. www.theglobeandmail.com/arts/art-and-architecture/articlethe-notre-dame-fire-was-a-warning-bell-but-will-europe-listen/. Accessed on: 29 Aug. 2019.

[34] Fleming, S., France wants to rebuild Notre Dame in just 5 years. Here's how new technology can help. World Economic Forum, 30 April 2019. www.weforum.org/ agenda/2019/04/france-wants-to-rebuild-notre-dame-in-just-five-years-here-s-hownew-technology-can-help/. Accessed on: 24 Aug. 2019.

[35] Trouillard, S. \& Mufson, C., Restoring Notre-Dame: Tough decisions ahead. France 24, 17 April 2019. www.france24.com/en/20190417-notre-dame-cathedral-firerestoration-realistic-macron-rebuild-five-years. Accessed on: 30 Aug. 2019.

[36] AP, Notre-Dame celebrates first Mass since devastating April fire. Sydney Morning Herald, 16 June 2019.

[37] Charlton, A., Lead scrubbed from Paris streets as Notre Dame work resumes. The Columbian, 19 August 2019. www.columbian.com/news/2019/aug/19/lead-scrubbedfrom-paris-streets-as-notre-dame-work-resumes/. Accessed on: 2 Sep. 2019.

[38] Marin, L., "We Will Rebuild": Macron vows to restore Notre-Dame within five years. France 24, 17 April 2019. www.france24.com/en/20190417-macron-vows-rebuildnotre-dame-five-years. Accessed on: 30 Aug. 2019. 
Disaster Management and Human Health Risk VI 63

[39] McCarthy, N., How much will it cost to repair Notre Dame?. Statista, 25 April 2019. www.statista.com/chart/17801/estimated-repair-costs-for-notre-dame/. Accessed on: 30 Aug. 2019. 